\title{
Victims of the Civil War and the Franco Repression in Asturias: A Provisional Balance
}

\author{
Carmen Garcia* \\ Department of History, Oviedo University, Spain \\ Received: 眥 May 24, 2018; Published: 莗 May 29, 2018 \\ *Corresponding author: Carmen Garcia, Department of History, Oviedo University, Spain
}

\section{Introduction}

Counting and naming the dead of armed conflicts, massacres and any historical traumatic event is not yet an easy task; even less if they mediated long decades with a dictatorship of almost forty years in between. More difficulties involve the localization in space of a large part of the fatalities resulting from irregular repression ("walks"), as well as that of hundreds of soldiers fallen on the front and so often poorly buried in improvised trenches or trenches. Counting, naming and, as far as possible, locating the burial sites were the basic objectives of the research project that since 2003 we have been carrying out at the University of Oviedo under the direction of who signs these pages. The initial impulse came from the petitions that descendants of the losers and associations committed to the signification of the victims of Franco's repression made to the Government of the Principality. The insistence of the so-called "memory entrepreneurs" prompted the signing of an agreement with the University of Oviedo, signed in 2003, and which aimed to locate the mass graves scattered in cemeteries, mountains, "praos", ditches, wells and natural chasms. In a first phase the project, called "Identification of common graves and other places of burial of missing persons as a result of the civil war", had only two fellows, Pedro Luis Alonso Garcia and Gustavo Alvarez Rico whose only stipend barely covered the expenses derived from the investigation.

Periodic, although discontinuous, renewals of the Agreement increased funding, with the commitment of the Ministry of Housing and Social Welfare, and the support it has provided since 2005 from the City of Gijon. This made it possible to expand the number of researchers and improve their working conditions somewhat. As of 2005, Irene Diaz Martinez, Amaia Caunedo Dominguez and, finally Claudia Cabrero Blanco joined the research project together with the aforementioned Pedro L. Alonso and Gustavo Alvarez. From the team I cannot fail to mention its methodological good work, its intellectual rigor, its ability to work beyond any contractual obligation; in short, his true "excellence". The approach of the academic research was from the first moment to know how many, who, when, where, in what circumstances and the reason for each and every one of the violent deaths derived from the war in Asturias. This included the combatants of both sides, the civilian victims, and of course, those produced by the repression carried out during the development of the conflict in both the loyal and the facciosa zones, and, of course, those that were the result of the unmerciful Francoist repression unleashed, between the noise and the fury of the victors, in a wide temporal space that includes since the fall of Asturias in October 1937 until 1952.

We start from the exhaustive management of the civil registries of the 78 Asturian councils, in addition to that of Lugo, emptied systematically from July 1936 to the present. The information on the death certificates served as a guideline to establish the 24 fields of the Database to which we added two more, that of Sources and the one of Concept. In the field Sources are cited all the documentary and oral references that we have gathered about each person, and in the field Concept we have classified the people based on 10 criteria: War Action, Civil Victim, Republican Repression, Francoist Repression, (murders and "walks" without any judicial process) Executed by the Republicans, Executed by the Francoists, (shot after being sentenced to the last penalty) Prisoner of the Republicans, Prisoner of the Francoists, (only violent deaths were collected while were detained) Guerrilla Repression, and finally Undetermined Cause, for those cases in which it was not possible to clearly establish the circumstances surrounding numerous deaths.

Of course, there is no doubt about the limitations of this primary source because, as is well known, not all victims were registered either at the time of death or later. In this regard, the very few casualties of "Moor" soldiers, or of militiamen killed in combat, are very striking, especially in the last months of the war, and of course, the absences of many of those killed in the repression are evident. "irregular". Of the approximately 27,000 people in the Database, about 7,000 were never recorded in the civil registries as was mandatory. Around 3,000 Republican soldiers killed in combat were to be included from the voluminous but incomplete internal 
documentation of the popular army (Battalion Statutes, Casualty Parts, Deceased Relations and Disappearances) preserved in the Archive of the Civil War of Salamanca and whose microfilm copy is deposited in the Historical Archive of Asturias.

Another problem of death certificates and not minor, is the fact that they do not always accurately mention the causes of death; often the blank box appears, or has been crossed out, or alludes to "cardiac failure", "respiratory failure", "collapse”, "traumatic shock", and in the inscriptions made later it is common to be noted as cause of death "the fight against Marxism" or "the last war", apostilles that cover so many times what had been a "walk", a murder, or a take-off, different modalities, in short, of the "irregular" repression . It was necessary to complement, contrast information, compare sources, add data, names, dates, places of burial, and clarify circumstances of the deaths. Without going into a detailed analysis of all the archives and sources consulted, I would like to mention some especially valuable for the investigation; For example, the parish and municipal archives, or the books of the cemeteries, the most exceptional for its rarity is, without a doubt, the "Record Book of Executions of the Cemetery of Oviedo". As if it were an accounting book, the chaplain administrator of the cemetery records day by day the list of executed and the place of burial, specifying whether the prisoners had confessed and communicated or not.

The prison archives were consulted systematically; files, files of prisoners, or the fragmentary documentation related to concentration camps such as the Vidriera de Aviles. At the same time information was incorporated from the actions of the People's Courts and, occasionally, the information provided by the War Councils. In the National Historical Archive is held the fund generated around the so-called General Cause, instructed by the Francoist judicial authorities in order to unveil the "excesses" committed during the "red domination." The voluminous information contained in the General Cause of the province of Oviedo has been fundamental to know in depth the republican repression; source that, in addition, was collated with varied local documentation. In this respect, the one preserved in the Municipal Archive of Gijon is particularly rich.

On the other hand, the documentation of the Archive of the Holy Cross of the Valley of the Fallen and the complementary preserved in the Historical Archive of Asturias allowed us to know in detail the transfer of remains from cemeteries and mass graves to the crypts of the Basilica del Valle. There ended the remains of some 3,000 fallen in the war, the vast majority belonging to the Francoist army but also houses some Republican soldiers, without ruling out the possible presence of victims of repression, buried in their day as "unidentified corpses."At the same time, we have handled hemerographic and bibliographic sources, as well as documents and information provided by associations and collaborators. In this order of things, it has been the oral testimonies that have provided crucial and valuable information for the investigation. In addition to providing invaluable information about names, places, or the circumstances that surrounded so many deaths not clarified in another way, survivors of the armed conflict and relatives of the reprisals have recounted their experiences, have recalled traumatic events and relived painful experiences that allow us to glimpse the subjugation to which the vanquished were subjected.

Not in vain one of the projects was called precisely "Voices of the past. Oral testimonies of repression and political violence in Asturias "in which Ruben Vega, a specialist in oral history and responsible for the Oral Sources Archive for the Social History of Asturias (AFOHSA), actively collaborated; in this file were deposited the series of interviews conducted by the research team in these years. Since the end of 2010, the "Map of Common Graves of Asturias" can be consulted on the Internet at the following address: http://tematico.asturias.es/fosas/index.htm. Later it was revised and edited on CD (Oviedo, 2011). It is an interactive map in which 343 burial sites have been located; For the most part they are graves of reprisals by the Franco regime, although some wellknown combatants have also been included. We have not indicated the pits of the republican repression since a good part of them were exhumed by the victors in the immediate postwar period. It should be pointed out that the great pits of Franco's repression are found in the cemeteries of Oviedo and Gijon, while a good number of municipal and some parochial cemeteries house pits; In addition, we have tried to locate as accurately as possible, from the sources and testimonies, all the remaining scattered throughout the region and, of course, cannot exclude other burial sites covered under the dense mantle of oblivion.

As for the "Database of victims of the Civil War and Franco's repression in Asturias" has been published on CD (Oviedo, 2011) and is deposited in the Historical Archive of Asturias. The figures not yet definitive, since we are still incorporating and reviewing new data, show us the harshness of the war and the repression in Asturias, measured in the very high number of victims that far exceed the 26,000 and certainly not all. By grouping the total figures by concepts, we can clearly establish that the highest number of deaths was, of course, a consequence of the war, almost 15,000 deaths in War Action and about 1,000 Civilians. Another incontestable fact is the magnitude of the Francoist repression; if we add "walks", executions and violent deaths of prisoners we find a total of 7,164 fatalities, many more than we had handled in previous estimates, and light years from the "exact figures" given by the historian Ramon Salas Larrazabal who it affirmed categorically that the number of deaths attributable to the Francoism in all Asturias added 2,037.

As for the volume of republican repression, of which we can offer practically definitive figures, it was characterized as having an "irregular" character; of the total of 2,013 victims, except for 53 executions ordered by the People's Courts, and 19 violent deaths of prisoners, the rest were the result of "walks", sacks and murders without any judicial procedure. On the other hand, fugitives and guerrillas were responsible for at least 166 deaths among members of the forces of order, Falangists, Somatenes and other personages 
of the regime actively engaged in the fight without quarter against those who fought with weapons in hand to the dictatorship. There are still a high number of violent deaths not clarified, in particular 1,353, which until now we have to include under the heading Cause not determined.

The research owes a lot to many people, and although this is not the time to quote a long list of informants and collaborators, if you would like to mention at least those who provided invaluable help in the preparation of the Map and the Base. Alfonso Camblor
Florez, draftsman of the Department of Geography and Claudia Pena Rosales, computer engineer, worked with boldness and generosity on the Map of Graves; at the same time Paloma Garcia Munoz, historian and archivist, designed with care and patience the Database in its current format. However, we cannot conclude the task; despite the scope of the investigation, we cannot even affirm that these are the "exact and definitive data" of the victims and the places. It is a project under construction and we have laid the foundations, nothing more and nothing less.

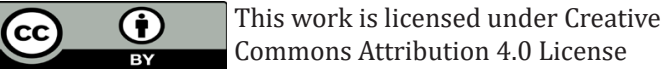

To Submit Your Article Click Here:

Submit Article

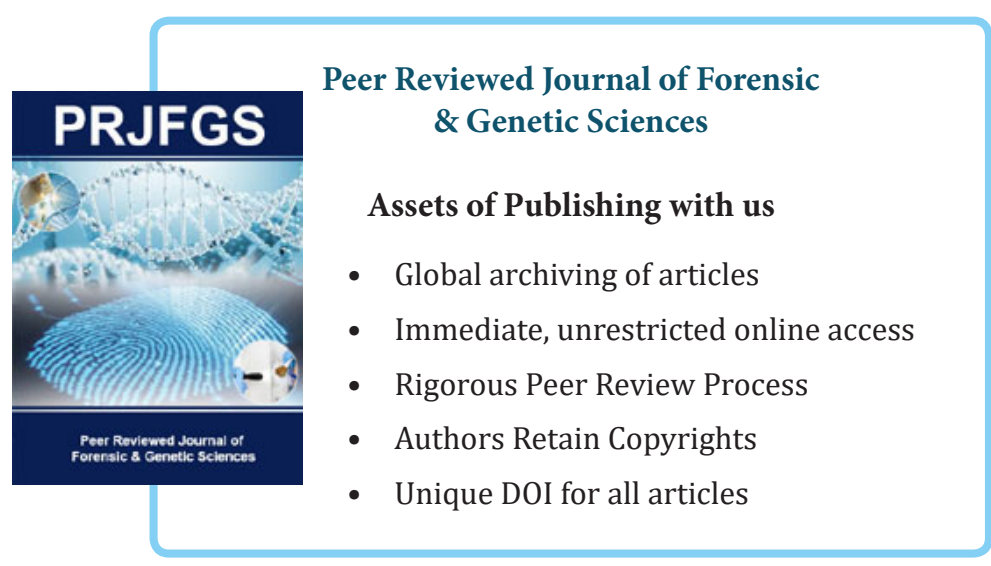

